\title{
Ferrite-Plated Thin Films for Perpendicular Recording Media
}

\author{
Yoshitaka KITAMOTO, Shusuke KANTAKE, and Masanori ABE
}

\author{
Department of Physical Electronics, Tokyo Institute of Technology \\ 2-12-1 O-okayama, Meguro-ku, Tokyo, 152, Japan
}

\begin{abstract}
Ferrite-plated films were studied for application as perpendicular recording media. Though the ferrite plating has a merit of low temperature process below $100{ }^{\circ} \mathrm{C}$, the microstructure must be improved for the media application. Power ultrasound irradiation into reaction solutions had effects on the reduction of grain size and the improvement of crystallinity maybe due to the increase of the nucleation sites on substrates and the acceleration of the ion migration in reaction. Doping $\mathrm{Co}^{2+}$ ions into $\mathrm{Fe}_{3} \mathrm{O}_{4}$ films increased perpendicular coercivity $\mathrm{H}_{\mathrm{cl}}$. $\mathrm{Co}_{\mathrm{x}} \mathrm{Fe}_{3-\mathrm{x}} \mathrm{O}_{4}$ plated films of $70 \mathrm{~nm}$ in thickness around at $\mathrm{x}=0.5$ had $\mathrm{H}_{\mathrm{c} \perp}$ of $2.8 \mathrm{kOe}, \mathrm{H}_{\mathrm{c} /}$ of $0.6 \mathrm{kOe}$, and $\mathrm{M}_{\mathrm{s}}$ of $450 \mathrm{emu} / \mathrm{cc}$. Mossbauer analyses showed the films have perpendicular anisotropy.
\end{abstract}

Key words: ferrite-plating, sonochemistry, power ultrasound, Coferrite, perpendicular recording media

\section{INTRODUCTION}

Ferrite thin film recording media have a good potential because of their low noise characteristics and good mechanical durability [1]. While physical vapor deposition methods, such as sputtering and evaporation, need high temperature over $300{ }^{\circ} \mathrm{C}$ for the ferrite film deposition and/or post-heating treatment, the "ferrite-plating" method facilitates to deposit polycrystalline spinel type of ferrite films at low temperature below $100{ }^{\circ} \mathrm{C}$ in aqueous solutions [2]. The ferrite-plated films in the former studies revealed columnar structure in the cross section and large grains near surface. Their structure will affect the recording performance in particular the noise characteristics. The structure is very similar to that of sputter-deposited films at high working gas pressures. This suggests that it is necessary to increase nucleation sites on substrates and to accelerate ion migration on growing films in order to deposit fine grained ferrite films. Thus, irradiation of power ultrasound during ferrite-plating was attempted. The power ultrasound enhancement in chemical reaction, called "sonochemistry," recently attracted considerable attention as a possible breakthrough in material science. A previous study on ultrasound enhanced ferrite-plating showed an improvement of $\mathrm{Fe}_{3} \mathrm{O}_{4}$ coatings on polyacrylate spheres of $0.25 \mu \mathrm{m}$ in average diameter [3].

Soft magnetic ferrite films of several hundreds nanometers or over one micron in thickness were studied in most of the former studies on the ferrite-plating. For application to perpendicular magnetic recording media, ferrite films with high perpendicular coercivity over $1 \mathrm{kOe}$ and the thickness below $100 \mathrm{~nm}$ are required. Thus addition of $\mathrm{Co}^{2+}$ ions was attempted to increase the coercivity and cause perpendicular anisotropy.

\section{EXPERIMENTAL}

As shown in Fig. 1, ultrasound waves $(19.5 \mathrm{kHz}, 600 \mathrm{~W})$ were applied by a horn $(30 \mathrm{~mm} \phi)$ into a reaction solution $(300 \mathrm{ml})$ of $\mathrm{FeCl}_{2}$ aqueous solution kept at $70{ }^{\circ} \mathrm{C}$. A $\mathrm{NaNO}_{2}$ solution was supplied to the solution to keep oxidation reduction potential (ORP) at $-500 \mathrm{mV}$, and $\mathrm{NH}_{4} \mathrm{OH}$ solution to keep the $\mathrm{pH}$ value at 7.0. For comparison, we also performed the ferrite plating without sonication, agitating the aqueous solution with a spinning stirrer which was replaced for the ultrasound horn and the spin-spray ferrite-plating [4]. $\mathrm{Fe}_{3} \mathrm{O}_{4}$ films were deposited on polyacrylate spheres, $4 \mu \mathrm{m}$ in average diameter, and glass substrates.

(Co, $\mathrm{Fe})_{3} \mathrm{O}_{4}$ films were prepared by the spin-spray ferrite-plating on glass substrates at $90^{\circ} \mathrm{C}$ using a reaction solution of $\mathrm{FeCl}_{2}+\mathrm{CoCl}_{2}$ and an oxidizing solution of $\mathrm{NaNO}_{2}+\mathrm{CH}_{3} \mathrm{COONH}_{4}(\mathrm{pH}=5 \sim 7)$.

The surfaces of the ferrite coatings on the spheres were observed by a field emission type scanning electron microscope (FE-SEM). The cross sections of the plated particles were observed by a transmission electron microscope (TEM) on ultramicrotome-slices $(60 \mathrm{~nm}$ in thickness) of an acrylate resin in which the particles were 
embedded. The surfaces of the films on the glass substrates were observed by AFM. The crystallographic and magnetic characteristics of the films were investigated at room temperature, using a $\mathrm{CuK} \alpha \mathrm{X}$-ray diffractometer, a $\mathrm{Co}^{57}$ Mössbauer spectrometer, and a vibrating sample magnetometer (VSM).

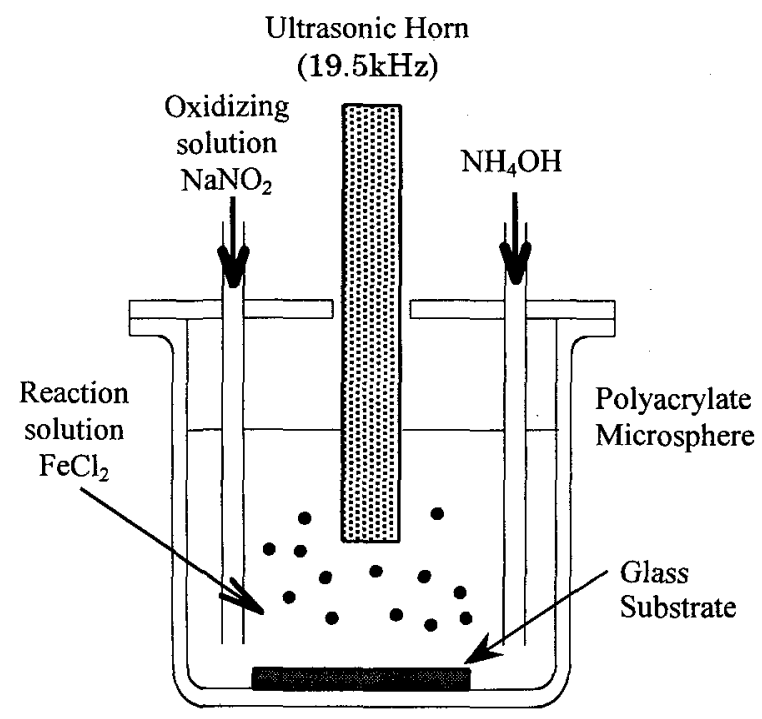

Fig. 1 Schematic diagram of ultrasound enhanced ferrite-plating apparatus.

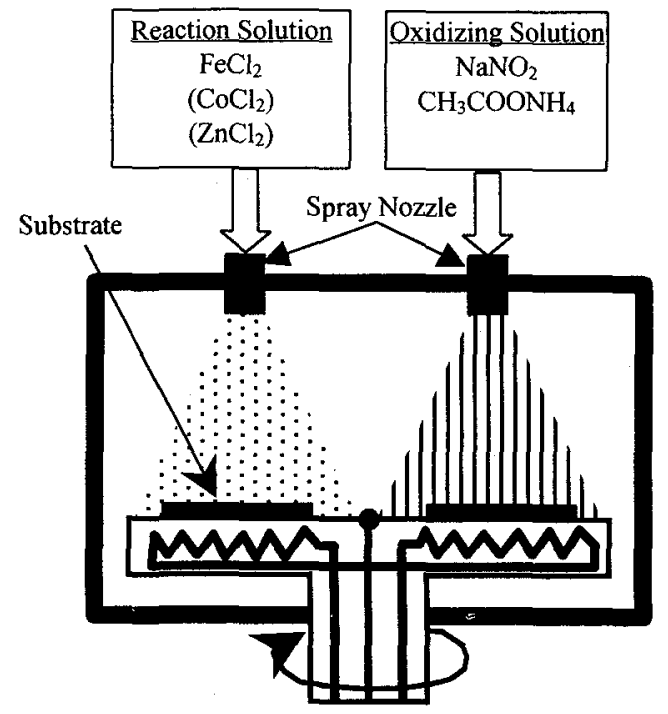

Fig. 2 Schematic diagram of spin-spray ferrite-plating apparatus.

\section{RESULTS AND DISCUSSION}

Figure 3 shows SEM photographs of $\mathrm{Fe}_{3} \mathrm{O}_{4}$ coated spheres after the reaction for 30 minutes. When plated with ultrasound irradiation, the spheres were encapsulated with $\mathrm{Fe}_{3} \mathrm{O}_{4}$ coating as shown in Fig.3(a). However, when plated without irradiation, the ferrite coating covered the surfaces only in part as shown in Fig.3(b). Figure 4 shows AFM images of the ferrite-plated films of $30 \mathrm{~nm}$ in thickness on glass substrates by (a) the ultrasound enhanced method and (b) the spin-spray method. Smaller and more uniform grains are observed in the Fig.4 (a) compared with (b). These results suggest that the number of nucleation sites on the substrates when plated with ultrasound irradiation is larger than that without the ultrasound. The power ultrasound generates in liquids localized "hot spots" of extremely high temperatures $(\sim 3,000 \mathrm{~K})$ and high pressures $(\sim 1,000 \mathrm{~K})$ due to collapse of cavitation bubbles, and the hot spots produce radicals such as $\mathrm{OH}^{*}$ and $\mathrm{H}^{*}$ in an aqueous solution [5]. The radicals may bring about $\mathrm{OH}$ groups, which works as the nucleation sites for the ferrite formation, on the substrates. In addition, the ultrasound irradiation should accelerate migration of ions in the solution and on the surfaces of the substrates. These two effects of the power ultrasound enhancement may help to produce the smaller and more uniform grains.

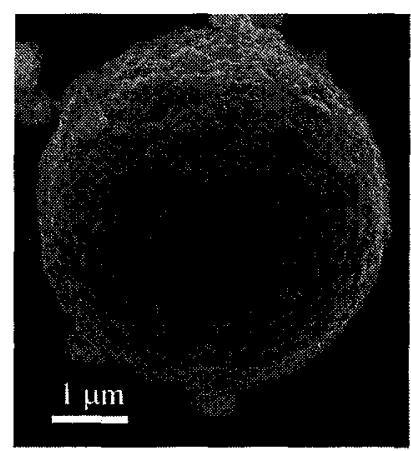

(a) with ultrasound irradiation

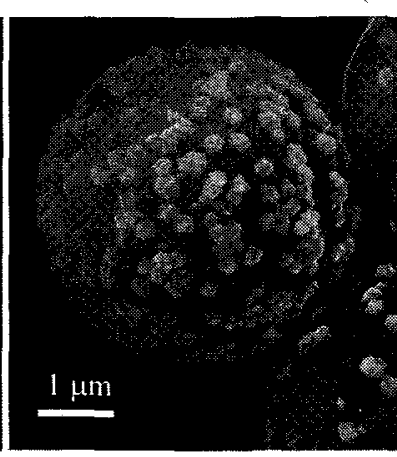

(b) without ultrasound irradiation
Fig. 3 SEM photographs of $\mathrm{Fe}_{3} \mathrm{O}_{4}$ coated spheres.

Figure 5 shows the dark field image of TEM cross sectional view for the ferrite-coated spheres with ultrasound irradiation. Parts, which are pointed out by arrows, are crystallites of the ferrite coating. The size is 
about $30 \mathrm{~nm}$. Figure 6 shows the electron diffraction patterns. The probe size is around one coated sphere. While spots, which reflect crystal orientation, are observed in Fig.6 (a) for the coated spheres with the ultrasound, the diffraction pattern of that without sonication is very close to rings as shown in Fig.6(b). These results suggest that crystallites of the ferrite coating by the sonicated plating are well oriented. Since the ultrasound irradiation accelerates the migration of ions, the ions should be trapped in the right sites to compose good crystallites.

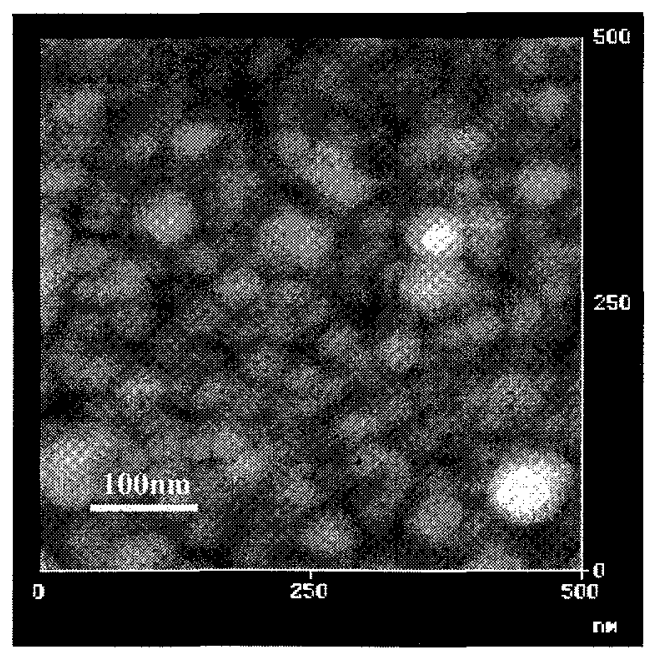

(a) ultrasound enhanced ferrite-plating

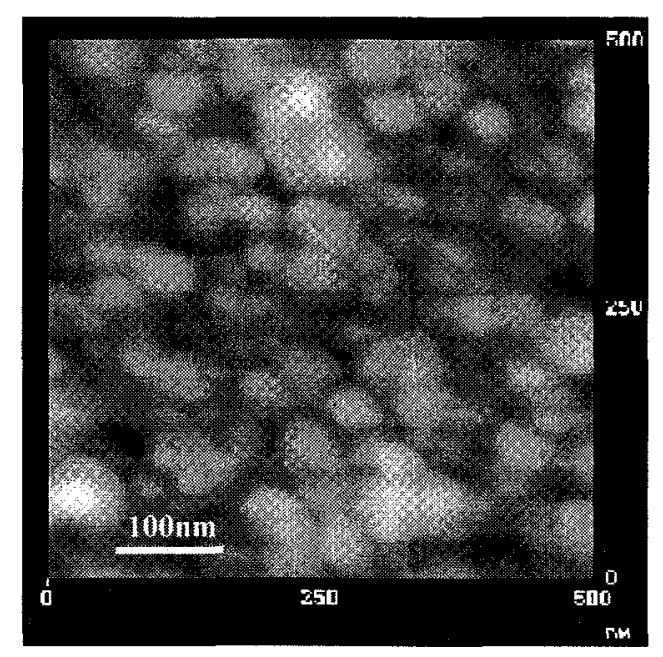

(b) spin-spray ferrite-plating

Fig. 4 AFM images of $\mathrm{Fe}_{3} \mathrm{O}_{4}$ films prepared on glass substrates.

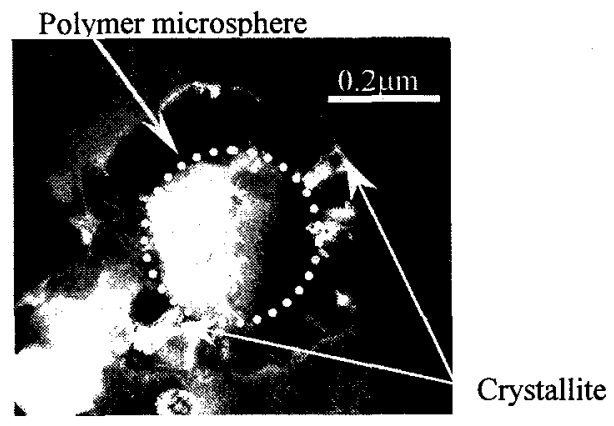

Fig. 5 TEM cross sectional view of $\mathrm{Fe}_{3} \mathrm{O}_{4}$ coated spheres prepared with ultrasound irradiation.

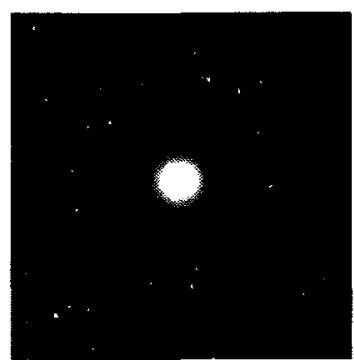

(a) with ultrasound irradiation

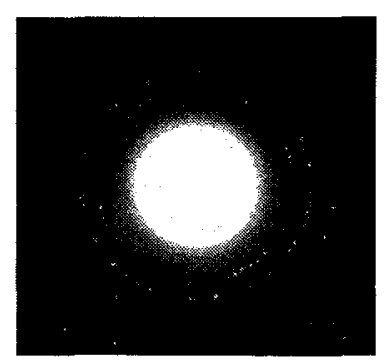

(b) without ultrasound irradiation
Fig. 6 Electron diffraction patterns of $\mathrm{Fe}_{3} \mathrm{O}_{4}$ films.

Doping of $\mathrm{Co}^{2+}$ ions into $\mathrm{Fe}_{3} \mathrm{O}_{4}$ films increased perpendicular coercivity $\mathrm{H}_{c \perp}$. Figure 7 shows the typical M-H loops of $\mathrm{Co}_{\mathrm{x}} \mathrm{Fe}_{3-\mathrm{x}} \mathrm{O}_{4}$ plated films. $\mathrm{H}_{\mathrm{c} \perp}$ for $50 \mathrm{~nm}$ thick films was varied from 0.4 to $2.2 \mathrm{kOe}$ with the ratio of $\mathrm{Co} / \mathrm{Fe}$ in the reaction solution and took a maximum around at $\mathrm{x}=0.5$, while $\mathrm{H}_{\mathrm{c} / /}$ remained around $0.2 \sim 0.8 \mathrm{kOe}$ as shown in Fig. 8. The magnetic characteristics did not depend strongly on the thickness of the films, and $\mathrm{H}_{\mathrm{c} \perp}$ for the films of only $30 \mathrm{~nm}$ in thickness was $2.3 \mathrm{kOe}$. Figure 9 shows a Mossbauer spectrum of $\mathrm{Co}_{0.43} \mathrm{Fe}_{2.57} \mathrm{O} 4$ films. In the case of perpendicular anisotropic films, the ratio of the peaks should be $3: 0: 1: 1: 0: 3$, and it should be $3: 2: 1: 1: 2: 3$ in the case of in-plane anisotropic ones. This spectrum is very similar to the perpendicular anisotropic ones. The results of $X$-ray diffractometry showed that these films did not have a specific preferential orientation. In this study, Co-ferrite films with $\mathrm{H}_{\mathrm{c} \perp}$ of $2.8 \mathrm{kOe}, \mathrm{H}_{\mathrm{c} / /}$ of $0.6 \mathrm{kOe},\left(\mathrm{M}_{\mathrm{r}} / \mathrm{M}_{\mathrm{s}}\right)_{\perp}$ of 0.5 (without compensation of demagnetizing field), $\left(\mathrm{M}_{\mathrm{r}} / \mathrm{M}_{\mathrm{s}}\right)_{/ /}$ of 0.24 , and $M_{s}$ of $450 \mathrm{emu} / \mathrm{cc}$ were deposited at the thickness of $70 \mathrm{~nm}$. These values are very close to sputterdeposited $\mathrm{Co}-\mathrm{Cr}$ alloy thin films. 


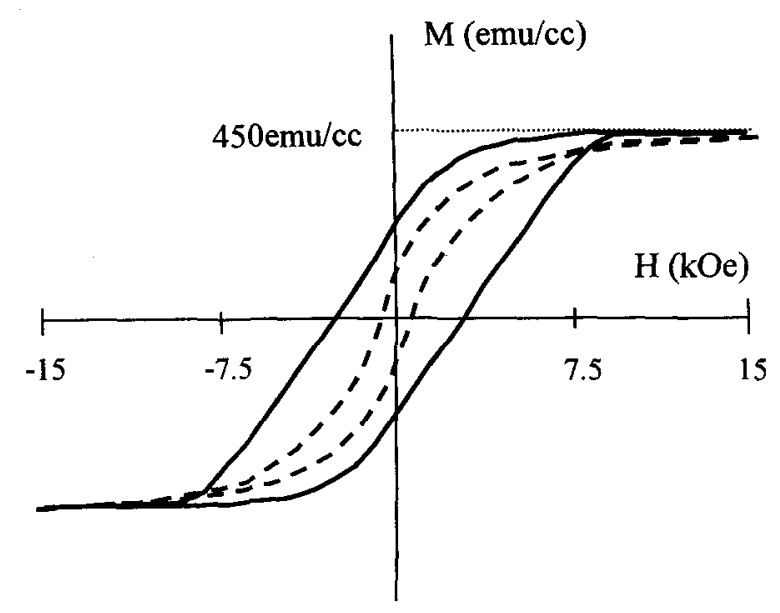

Fig. 7 M-H loops of $\mathrm{Co}_{\mathbf{x}} \mathrm{Fe}_{3-\mathrm{x}} \mathrm{O}_{4}$ films.

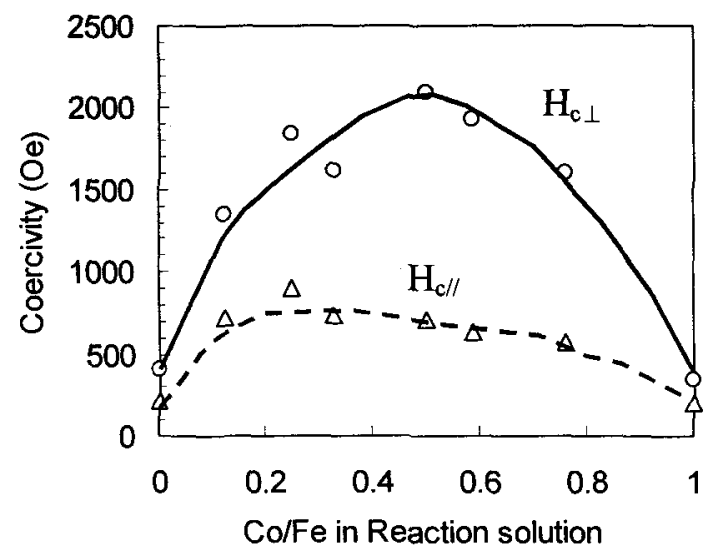

Fig. 8 Dependence of coercivity on $\mathrm{Co} / \mathrm{Fe}$ ratio in reaction solution.

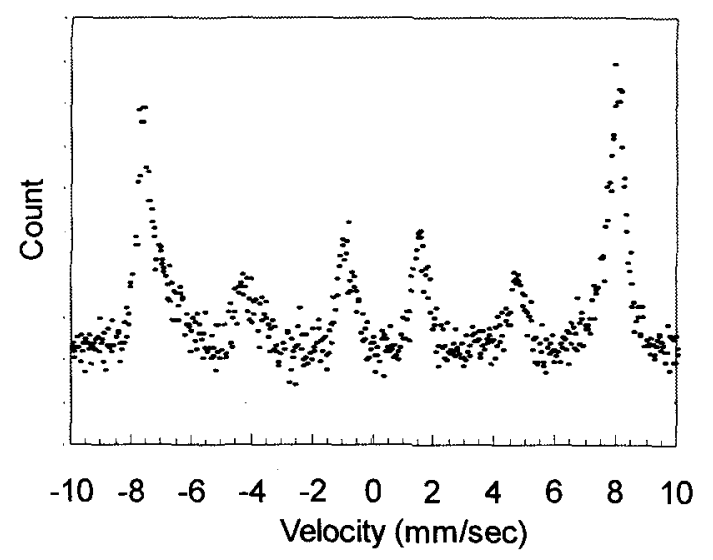

Fig. 9 Mossbauer spectrum of $\mathrm{Co}_{0.43} \mathrm{Fe}_{2.57} \mathrm{O}_{4}$ films.

\section{CONCLUSION}

Aiming applications as perpendicular recording media, we investigated improvements of microstructure and magnetic characteristics of ferrite-plated films. Power ultrasound irradiation into reaction solutions has effects on the reduction of grain size and the improvement of crystallinity. The increase of the nucleation sites and the acceleration of the ion migration by the ultrasound enhancement are thought to cause the structural improvement. Doping $\mathrm{Co}^{2+}$ ions into $\mathrm{Fe}_{3} \mathrm{O}_{4}$ films increased $\mathrm{H}_{c \perp}$ and caused perpendicular anisotropy. $\mathrm{Co}_{\mathrm{x}} \mathrm{Fe}_{3 \cdot \mathrm{x}} \mathrm{O}_{4}$ plated films have the magnetic characteristics close to Co$\mathrm{Cr}$ alloy films, and the magnetic characteristics of the films of $70 \mathrm{~nm}$ in thickness around at $\mathrm{x}=0.5$ are as follows; $H_{c \perp}$ of $2.8 \mathrm{kOe}, \mathrm{H}_{\mathrm{c} / /}$ of $0.6 \mathrm{kOe}$, and $\mathrm{M}_{\mathrm{s}}$ of $450 \mathrm{emu} / \mathrm{cc}$.

\section{ACKNOWLEDGEMENT}

This study has been financially supported in part by the "Research for the Future" Program, \#JSPSRFTF96R06901, from the Japan Society for the Promotion of Science.

\section{REFERENCES}

[1] S. Tsuboi, T. Korenari, N. Ishiwata, K. Yamada, and K. Tagami, "Noise characteristics for $\mathrm{Co}-\mathrm{Cr}$-Ta media and ferrite media," J. Magn. Soc. Jpn., vol.18, Suppl. No.S1, pp.95-98, 1994.

[2] M. Abe and Y. Tamaura, "Ferrite plating in aqueous solution: New technique for preparing magnetic thin film," J. Appl. Phys., vol.55, pp.2614-2616, 1984.

[3] Y. Kitamoto, M. Zhang, S. Haijima, K. Matsumoto, and M. Abe, "Ultrasound Enhanced Ferrite Plating," Proceedings of $7^{\text {th }}$ ICF, J. PHYS IV FRANCE vol.7, Colloque C1, Supplement au Journal de Physique III, pp.C1-581-582 (1997).

[4] M. Abe, Y. Tamaura, M. Oishi, T. Saitoh, T. Itoh, and M. Gomi, "Plating of ferrite films on 8 " disc at $70^{\circ} \mathrm{C}$ by spray-spin-coating method," IEEE Trans. Magn., vol.23, pp.3432-3434, 1987.

[5] T. J. Mason, "Sonochemistry: a technology for tomorrow," Chem. Industry, vol.18, pp.47-50, January, 1993. 